\title{
Prevalence of Malocclusions and Normative Orthodontic Treatment Need Using IOTN Index for Patients in Yalgado Ouédraogo Teaching Hospital
}

\author{
Youssouf Ouédraogo ${ }^{*}$, Tiécoura Camara², Raoul Bationo3 ${ }^{3}$, Loubna Bahije ${ }^{4}$, Jean Bertin Beugré5, \\ Joseph Samba Diouf6, Papa Ibrahima Ngom ${ }^{6}$
}

${ }^{1}$ Centre Hospitalier Universitaire Yalgado Ouédraogo, Université Ouaga I, Ouagadougou, Burkina Faso

${ }^{2}$ Direction de la lute contre la maladie, Ouagadougou, Burkina Faso

${ }^{3}$ Service de chirurgie dentaire du camp Sangoulé Lamizana, Ouagadougou, Burkina Faso

${ }^{4}$ Faculté de Médecine Dentaire, Université Mohammed V, Rabat, Maroc

${ }^{5}$ UFRd'odonto-stomatologie, Université Félix Houphouet Boigny, Abidjan, Côte D’Ivoire

${ }^{6}$ Institut d'odonto-stomatologie, Université Cheikh Anta Diop, Dakar, Sénégal

Email: ^ouedraogoy@yahoo.fr

How to cite this paper: Ouédraogo, Y., Camara, T., Bationo, R., Bahije, L., Beugré, J.B., Diouf, J.S. and Ngom, P.I. (2017) Prevalence of Malocclusions and Normative Orthodontic Treatment Need Using IOTN Index for Patients in Yalgado Ouédraogo Teaching Hospital. Open Journal of Stomatology, 7, 519-529.

https://doi.org/10.4236/ojst.2017.712049

Received: November 18, 2017 Accepted: December 17, 2017 Published: December 20, 2017

Copyright () 2017 by authors and Scientific Research Publishing Inc. This work is licensed under the Creative Commons Attribution International License (CC BY 4.0).

http://creativecommons.org/licenses/by/4.0/

\begin{abstract}
Introduction: The assessment of health care needs must be reproducible, independent of the operator, hence the use of indexes like the Index of Orthodontic Treatment Need (IOTN). The aim of this study was to assess both, the prevalence of malocclusions among patients received in the Dental Surgery Unitat Yalgado Ouédraogo Teaching Hospital and their care needs according to IOTN index. Materials and Methods: It is a prospective, cross-cutting diagnostic study of malocclusions at Yalgado Ouédraogo Teaching Hospital (CHUYO), conducted from January 1 to December 31, 2016. The examiner with an examination tray records on the 12- to 16-year-old patients' medical recorded, the variables based on the polychromatic pictures series, the IOTN rule, and the dental health component table. Results: On the whole, 81 patients were included, with $60.5 \%$ of girls and $39.5 \%$ of boys. 16- and 12 -year-old patients were dominant. The average age was 14.05 years old. Various types of malocclusions were encountered. The need for orthodontic care was $56.8 \%$. For 14 patients, $17.28 \%$, their aesthetic component score is higher than the assessment made by the orthodontist. Conclusion: Aesthetics was an important factor in the need for orthodontic care. The aesthetic deficit entails a psychological impact that should be taken into account in the assessment of care needs.
\end{abstract}




\section{Keywords}

Malocclusions, Orthodontic Care, IOTN, Burkina Faso

\section{Introduction}

Orthodontic abnormalities cover a various set of clinical situations, the assessment of which is often subjective. They can be sources of malfunctioning or aesthetic deficit. The need for the treatment of malocclusions is due, on the one hand, to care provision, and on the other hand, to the patient's financial positions and to how the patient cares for his or her oral health. These treatments are generally expensive and long lasting.

Treatment needs may be difficult to assess and vary by practitioner or patient. Treatment decision must be based on objective criteria [1] [2]. Thus, accurately assessing the care needed is an approach that must be duplicable, irrespective of the practitioner together with a universal language accessible to all stakeholders (practitioner, patients, insurance, health mutual). For this, several indexes have been created as the IOTN index (Index of Orthodontic Treatment Need) [3] [4] or index of need for orthodontic treatment, which enables a classification of the malocclusion of each patient by scoring it. It is easy to use and to be reproduced. The score varies according to the level of severity of the anomaly. It is proportional to the need for treatment according to two components: a Dental Health Component (DHC) and an Aesthetic Component (AC).

In literature, authors like Utomi et al. [1] found the need for orthodontic care in $68 \%$ of patients in a university hospital center in Nigeria.

The aim of this study is to describe the malocclusions in patients received in consultation in the Dental Surgery Unit of the Yalgado Ouedraogo Teaching Hospital and assess their care needs with reference to IOTN index.

\section{Material and Method}

\subsection{Framework and Study Type}

This is a diagnostic, prospective, cross-cutting descriptive study conducted from January to December 2016 focusing on dental malocclusions and normative needs in orthodontics care among the population. It was conducted in Burkina Faso, in the Dental Surgery Unit of the Yalgado Ouédraogo Teaching Hospital Center.

\subsection{Inclusion Criteria}

The patient must be aged between 12 and 16 years at the time of the consultation in this unit during the survey period and agree to participate in the study.

\subsection{Exclusion Criteria}

Any under 12-year patient or any patient beyond 16 years and any patient who has received orthodontic treatment were excluded from the sample. 


\subsection{Sampling}

The sampling was at random or fortuitous. We selected all patients received for orthodontic consultation from January 1 to December 31, 2016.

\subsection{Data Collection}

The examiner, equipped with an examination tray, reported on the patient's sheet, the variables listed according to the series of full-color photographs (Figure 1), the IOTN rule (Figure 2) and the dental health table (Table 1).
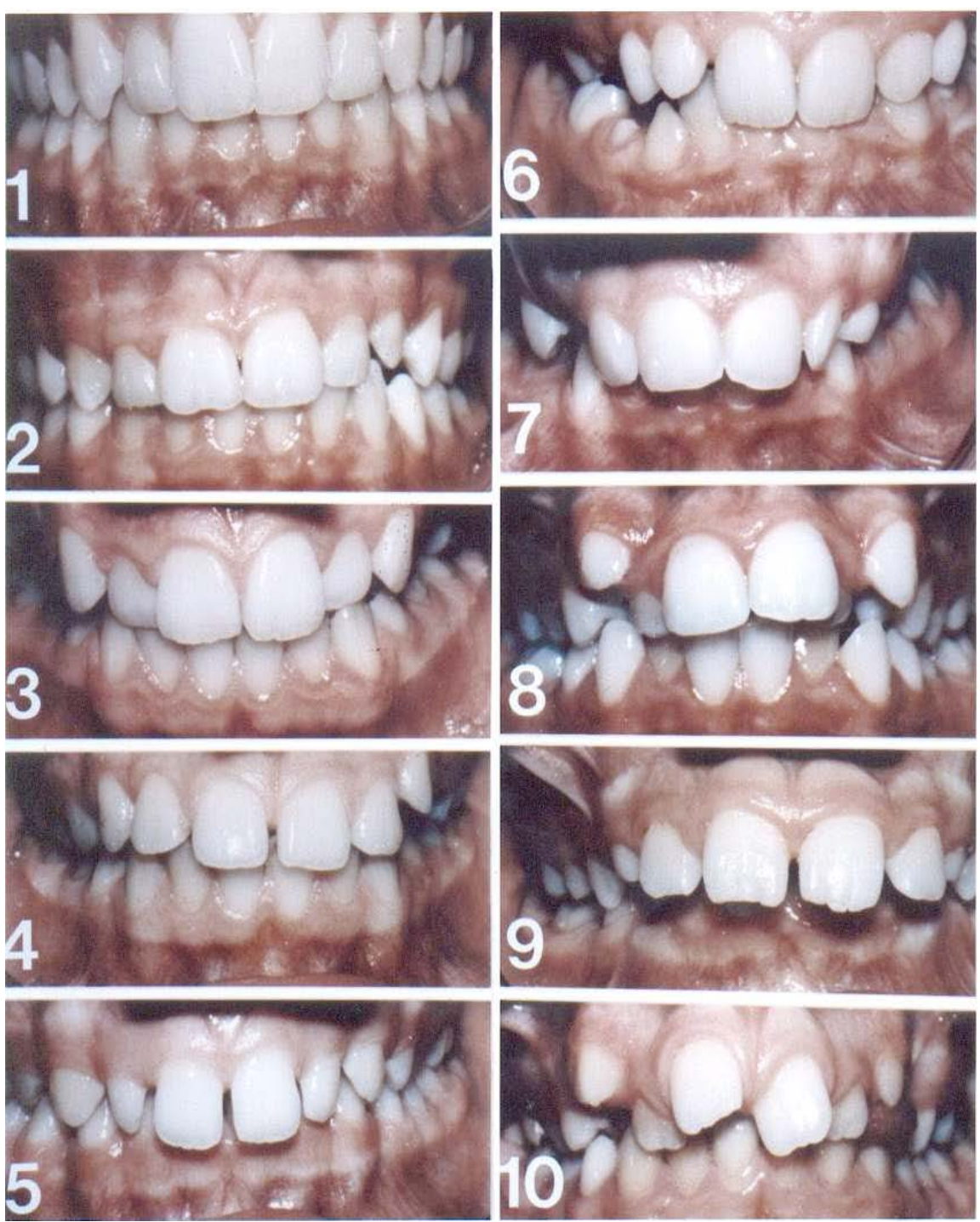

Figure 1. IOTN aesthetic sheet to conduct a direct assessment on the patient [3].

\begin{tabular}{|c|c|c|c|c|}
\hline $\begin{array}{l}0 \\
2\end{array}$ & \begin{tabular}{|l|l|}
3 & \\
$\mathrm{i}$ & 4 \\
2 & \\
$\mathrm{c}$ & \\
\end{tabular} & $\begin{array}{l}5 \text { Defect of CLP } \\
5 \text { Non-eruption of teeth } \\
5 \text { Extensive hypodontia } \\
4 \text { Less extensive hypodontia }\end{array}$ & $\begin{array}{l}3 \text { O.B. with } \mathrm{NO} \mathrm{G}+\mathrm{P} \text { trauma } \\
3 \text { Crossbite } 1-2 \mathrm{~mm} \text { discrepancy } \\
20 . \mathrm{B}>- \\
2 \mathrm{Dev} \text { from full interdig }\end{array}$ & $\begin{array}{l}\text { DISPLACEMENT } \\
\text { OPEN BITE } \\
\text { V }\end{array}$ \\
\hline 3 & I & 4 Crossbite $>2$ mm discrepancy & 2 Crossbite $<1 \mathrm{~mm}$ discrepancy & \\
\hline & $-m s-5$ & 4 O.B. with $\mathrm{G}+\mathrm{P}$ trauma & IOTN@Victoria University of Manchester & 43 \\
\hline
\end{tabular}

Figure 2. Small ruler dental health component measurement [3]. 
Table 1. Dental health component [3].

\begin{tabular}{|c|c|c|}
\hline Level 5 & a & Exaggerated over jet $>9 \mathrm{~mm}$ \\
\hline & h & Multiple ageneses with use of prosthetic implications (more than one teeth). \\
\hline & $\mathrm{i}$ & Missing by quadrant requiring pre-restorative orthodontic. \\
\hline & $\mathrm{m}$ & $\begin{array}{l}\text { Impacted teeth (except the third molars) due to a discrepancy, } \\
\text { a relocation, supernumerary teeth, temporary teeth that are not } \\
\text { exfoliated or any other pathology. }\end{array}$ \\
\hline & $\mathrm{p}$ & $\begin{array}{l}\text { Reversed over jet }>3.5 \mathrm{~mm} \text { with difficulties of chewing or speaking reported } \\
\text { by the patient. }\end{array}$ \\
\hline & s & Sequel of labio-alveolar fissure and/or palatines or temporary submerged teeth. \\
\hline \multirow[t]{11}{*}{ Level 4} & a & Increased over jet $>6 \mathrm{~mm}$ but $\leq 9 \mathrm{~mm}$. \\
\hline & $\mathrm{b}$ & $\begin{array}{l}\text { Reverse occlusion with over jet }>3.5 \mathrm{~mm} \text { with no chewing or speaking } \\
\text { difficulties reported by the patient. }\end{array}$ \\
\hline & c & $\begin{array}{l}\text { Posterior and anterior cross occlusion with a gap }>2 \mathrm{~mm} \text { between the } \\
\text { centered position and the maximal intercuspidity. }\end{array}$ \\
\hline & $\mathrm{d}$ & Relocation of the contact points $>4 \mathrm{~mm}$. \\
\hline & $\mathrm{e}$ & Anterior or lateral infracclusion $>4 \mathrm{~mm}$. \\
\hline & $\mathrm{f}$ & Severe and complete supraclusion with associate labial or palatine trauma. \\
\hline & $\mathrm{h}$ & $\begin{array}{l}\text { Less serious agenesis (no more than one missing tooth per quadrant) } \\
\text { requiring pre-prosthetic orthodontics or an orthodontic closing of the } \\
\text { space to avoid bearing dental prosthesis. }\end{array}$ \\
\hline & 1 & $\begin{array}{l}\text { Posterior linguoclusion with the lack of functional occlusal area in one or both } \\
\text { lateral segments of the dental arch. }\end{array}$ \\
\hline & $\mathrm{m}$ & $\begin{array}{l}\text { Reverse occlusion }>1 \mathrm{~mm} \text {, but } \leq 3.5 \mathrm{~mm} \text { with difficulties of shewing or } \\
\text { speaking recorded by the practitioner. }\end{array}$ \\
\hline & $\mathrm{t}$ & Partial eruption of teeth inclined or locked against the adjacent teeth. \\
\hline & $\mathrm{x}$ & Supernumerary teeth. \\
\hline \multirow[t]{6}{*}{ Level 3} & a & Increased over jet $>3.5$ but $\leq 6 \mathrm{~mm}$ with labial inocclusion. \\
\hline & $\mathrm{b}$ & Reverse occlusion $>1 \mathrm{~mm}$ but $\leq 3.5 \mathrm{~mm}$. \\
\hline & c & $\begin{array}{l}\text { Posterior and anterior cross occlusion with a gap }>1 \mathrm{~mm} \text { but } \leq 2 \mathrm{~mm} \\
\text { between the position of centered relation and the maximal intercuspidity. }\end{array}$ \\
\hline & $\mathrm{d}$ & Moving of the points of contact $>2 \mathrm{~mm}$ but $\leq 4 \mathrm{~mm}$. \\
\hline & $\mathrm{e}$ & Anterior or lateral infraclusion $>2 \mathrm{~mm}$ but $\leq 4 \mathrm{~mm}$. \\
\hline & $\mathrm{f}$ & Exaggerated and complete over jet without gingival trauma. \\
\hline \multirow[t]{7}{*}{ Level 2} & a & Exaggerated over jet $>3.5 \mathrm{~mm}$ and $\leq 6$ with labial occlusion. \\
\hline & $\mathrm{b}$ & Overturned overjet $>0 \mathrm{~mm}$, but $\leq 1 \mathrm{~mm}$. \\
\hline & c & $\begin{array}{l}\text { Anterior or posterior cross occlusion with a space } \leq 1 \mathrm{~mm} \text { between the } \\
\text { centered position and the maximal intercuspidity one. }\end{array}$ \\
\hline & $\mathrm{d}$ & Moving of the contact area $>1 \mathrm{~mm}$ but $\leq 2 \mathrm{~mm}$. \\
\hline & $\mathrm{e}$ & Anterior or posterior infraclusion $>1 \mathrm{~mm}$ but $\leq 2 \mathrm{~mm}$. \\
\hline & $\mathrm{f}$ & Exaggerated supraclusion $\geq 3.5 \mathrm{~mm}$ without gingival contact. \\
\hline & g & $\begin{array}{l}\text { Posterior and anterior occlusion almost normal without other abnormalities } \\
\text { with an offset less than a } 1 / 2 \text { tooth. }\end{array}$ \\
\hline Level 1 & & Minor malocclusion with small off set $<1 \mathrm{~mm}$. \\
\hline
\end{tabular}

The collection of photographs (Figure 1) is classified on a scale of 1 to 10 according to their attraction; 1 being the most attractive value and 10 the least at- 
tractive. This assessment of the dental aesthetic is done directly on the patient. The level of attractiveness of the patient's smile is classified by both, the patient, then the practitioner:

-from level 1 to level 4, there is no need for treatment or this need is low;

-from level 5 to level 7 , this requires moderate treatment; and

- from level 8 to level 10, the need for treatment is obvious.

The dental index is calculated from dental parameters measured using directly the ruler on the patient with reference to the table of the dental health component (Table 1). These dental parameters are classified from 1 to 5 :

-levels 4 and 5; the need for treatment is established;

-levels 3; this requires moderate treatment;

-levels 1 and 2; no or limited treatment required.

\subsection{Data Processing}

Data were manually analyzed and then processed with SPSS (Statistical Package of the Social Science) Software version 21. The processing was performed with the Software Office 2013 version. The quantitative variables were described according to their number and their rate with the significance level $p=0.05$. Qualitative variables were described by their regularity and rates. Cohen's Kappa nonparametric test was used to estimate the correlation between patient and practitioner scores. The confidentiality of data collected and patient anonymity were maintained throughout the study.

\section{Results}

Out of the 290 patients received in consultation over the period, 81 met the inclusion criteria and were therefore involved in the study.

\subsection{Patients' Social Characteristics}

Patients' age is given in Figure 3. Consultation at 16 years is the most frequent, with 22 patients $(17.82 \%)$. The average age was $14.05 \pm 1.56$ years. Concerning gender, there were 32 boys or $39.5 \%$ against 49 girls or $60.5 \%$ of the number of both categories. Gender ratio is 0.65 .

\subsection{Malocclusions Rate}

\subsubsection{Aesthetic Component}

The patient's perception of his malocclusion is mainly between 2 and 6 for $72.8 \%$ of patients. In this same score range, the practitioner classifies $76.6 \%$ of patients. For a score less than or equal to $5 ; 49$ patients are ranked against 53 according to the practitioner. Some patients outperform their score. The Table 2 reports the various scores on aesthetic.

\subsubsection{Dental Health Component}

The pathologies listed were diverse, including sagittal, vertical and transverse cases. It appears that our patients suffered from dental abnormalities both in 


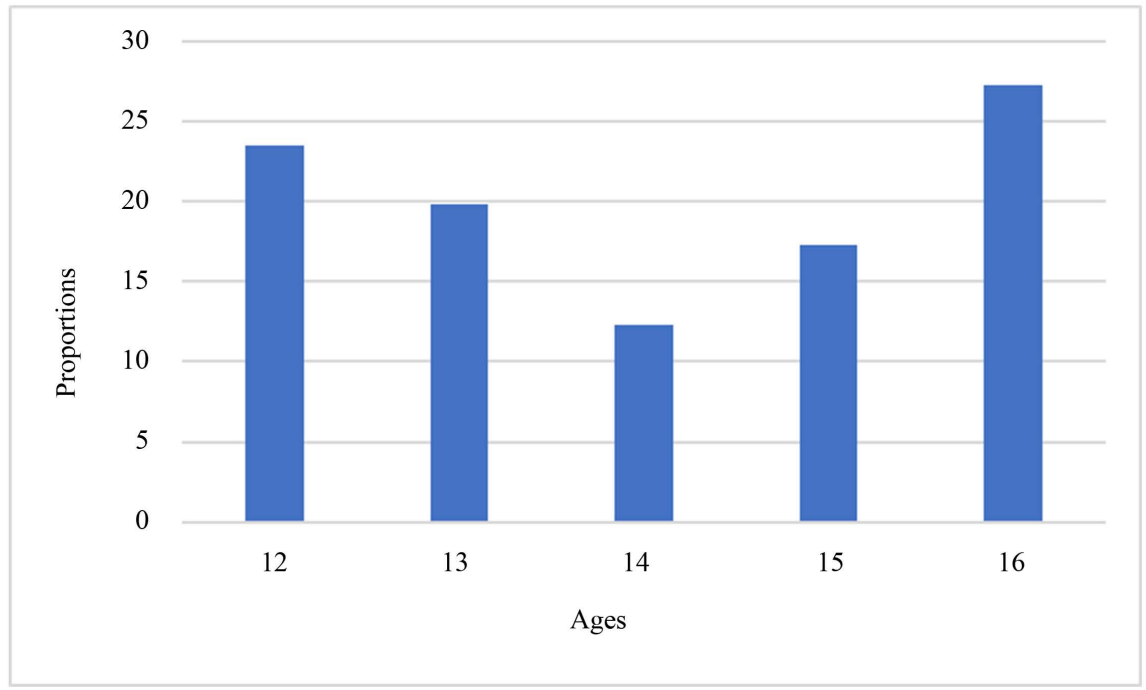

Figure 3. Patients distribution per age.

Table 2. Aesthetic component.

\begin{tabular}{ccccc}
\hline \multirow{2}{*}{ Score } & \multicolumn{2}{c}{ Per patient } & \multicolumn{2}{c}{ Per practitioner } \\
\cline { 2 - 5 } & Number & Rate & Number & Rate \\
\hline 1 & 1 & 1.2 & 1 & 1.2 \\
2 & 14 & 17.3 & 16 & 19.8 \\
3 & 13 & 16.0 & 12 & 14.8 \\
3 & 10 & 12.3 & 8 & 9.9 \\
5 & 11 & 13.6 & 16 & 19.8 \\
6 & 11 & 13.6 & 10 & 12.3 \\
7 & 7 & 8.6 & 6 & 7.4 \\
8 & 8 & 9.9 & 7 & 8.6 \\
9 & 4 & 4.9 & 4 & 4.9 \\
10 & 2 & 2.5 & 1 & 1.2 \\
Total & 81 & 100 & 81 & 100 \\
\hline
\end{tabular}

position and number. Table 3 reports these various malocclusions. Agenesis and dental avulsions were less frequent; they only concern 4 patients. Den to-maxillary disharmony, deficiency or excess are the most encountered with a score equal to or greater than 2 for displacement of contact point in $77.8 \%$ of patients.

\subsection{Care Need}

The previous pathologies required appropriate care among these patients received in consultation. More than the half $(56.8 \%)$ clearly needed to receive care according to their IOTN index (Table 4). The assessment of the aesthetic aspects by patients is consistent with that of practitioners in $81.48 \%$ of cases. Only one 
Table 3. Dental health component.

\begin{tabular}{|c|c|c|c|c|}
\hline \multirow{2}{*}{ Pathology } & \multicolumn{2}{|c|}{ Gender } & \multirow{2}{*}{$\begin{array}{c}\text { Total } \\
81\end{array}$} & \multirow{2}{*}{$\begin{array}{l}\text { Rate } \\
100 \%\end{array}$} \\
\hline & Boys $(\mathrm{n}=32)$ & Girls $(\mathrm{n}=49)$ & & \\
\hline \multicolumn{5}{|l|}{ Missing teeth: } \\
\hline Avulsions & 1 & 1 & 2 & 2.5 \\
\hline Agenesis & 0 & 2 & 2 & 2.5 \\
\hline Inclusions & 3 & 9 & 12 & 14.8 \\
\hline \multicolumn{5}{|l|}{ Overjet: } \\
\hline$<0$ & 8 & 5 & 13 & 16 \\
\hline $0-3.5$ & 20 & 38 & 58 & 71.6 \\
\hline $3.5-6$ & 4 & 5 & 9 & 11.1 \\
\hline \multicolumn{5}{|c|}{ Reverse occlusion: } \\
\hline Yes & 9 & 11 & 20 & 24.7 \\
\hline No & 23 & 38 & 61 & 75.3 \\
\hline \multicolumn{5}{|l|}{ OIM/RC: } \\
\hline $0-1$ & 21 & 40 & 61 & 75.3 \\
\hline $1-2$ & 11 & 9 & 20 & 24.7 \\
\hline \multicolumn{5}{|c|}{$\begin{array}{c}\text { Displacement of } \\
\text { contact point }\end{array}$} \\
\hline $0-1$ & 1 & 2 & 3 & 3.7 \\
\hline $1-2$ & 3 & 11 & 14 & 17.3 \\
\hline $2-4$ & 14 & 17 & 31 & 38.3 \\
\hline$>4$ & 14 & 18 & 32 & 39.5 \\
\hline \multicolumn{5}{|c|}{$\begin{array}{l}\text { Incisors vertical } \\
\text { relationship }\end{array}$} \\
\hline$<0$ & 3 & 7 & 10 & 12.3 \\
\hline $0-1$ & 12 & 8 & 20 & 24.7 \\
\hline $1-2$ & 6 & 21 & 27 & 33.3 \\
\hline $2-4$ & 9 & 8 & 17 & 21.3 \\
\hline$>4$ & 2 & 5 & 7 & 8.6 \\
\hline
\end{tabular}

Table 4. Orthodontic care needs.

\begin{tabular}{ccc}
\hline Care need & Number & Rate \\
\hline No & 7 & 8.6 \\
Moderate & 28 & 34.6 \\
Established & 46 & 56.8 \\
Total & 81 & $100 \%$ \\
\hline
\end{tabular}

patient had a score lower than that found by the practitioner. Concerning the other 14 patients or $17.28 \%$, their scores are higher than the practitioner's as- 
sessment. Patients tended to overestimate their dental abnormalities. The difference is statistically significant with $t=3.32$ for a confidence level of 0.05 . However, Cohen's nonparametric kappa test (test that measures inter-judges fidelity; when the judges have a high degree of agreement the value is close to 1 , otherwise the value is close to 0 ) gave a good correlation between the patient and practitioner scores at 0.77 .

\section{Discussion}

\subsection{Method Quality and Validity}

There are several orthodontic indexes to quantify abnormalities and the degree at which they require treatment. The ideal index must be [5]:

-flexible (it must enable to make measurements at different times and with different practitioners);

— valid (assess what it is made for);

-changeable;

— quantified by the parameters assessed;

-implemented quickly by qualified practitioners.

Among the main orthodontic indexes [6]-[11]: DAI (Dental Aesthetic Index), ICON (Index of Complexity, Outcome and Need), we have chosen IOTN (Index of Orthodontic Treatment Need) developed in 1989 by Shaw for its easy implementation and reproducibility. However, this index does not specify the psychological impact of malocclusion and its impact on the patient's life quality [12].

\subsection{Patients' Social Characteristics}

Girls are more numerous to consult. It is true that they represent the majority of our population [13]. In addition, they are more concerned about their appearance. Aesthetics ranks top among their reasons for consultation.

Our results reveal a high rate of consultation for the 16-year-old and then 12 -year-olds. Indeed, at 12 years, this corresponds to the appearing of all the permanent teeth, excepted wisdom teeth. An assessment of care needs is objective at this period. It is usually at this age that multi-band orthodontic treatment starts. Moreover, health insurances and health-care mutual are often reluctant to cover orthodontic care started after 16-year-olds. Financial constraints may account for so many consultations at this age.

\section{Malocclusions Prevalence and Care Needs}

Our sample includes patients in consultation. They are either referred or come on their own for an orthodontic consultation. As a result, they all have abnormalities at different levels of severity. Nevertheless, it appears that $8.6 \%$ do not require any care need according to IOTN index. The need for treatment was necessary in $91.4 \%$. This score is comparable to those found in patients by Bourne et al. [14] and Ghijselings et al. [15] at 78\% and $80.3 \%$, respectively. Yet, these are higher than the rates of $42.6 \%$ and $27.3 \%$ in the respective studies by Ngom 
et al. [16] and Perillo et al. [17] involving Senegalese and Italian school children. This difference can be explained by the fact that, since school children are not a consulting population, the prevalence of orthodontic anomalies is necessarily lower, at first sight.

Also, our results show that patients tend to overestimate their dental misalignments according to the aesthetic component compared to practitioner's opinion. Among school adolescents in Nigeria, Aikins et al. [18] find a significant difference between the assessment made by patients due to aesthetic reasons and that made by orthodontists

This negative perception of one's malocclusion has a psychological impact that motivates the consultation. According to Kolawole et al. [19], with equal pathology, the psychological impact of dental esthetics varies significantly from one schoolchild to another. This psychological component should also be taken into account in care needs. The individual infected may see his or her malocclusion differently, and the way he or she takes it is not necessarily due to its severity [20] [21].

\section{Conclusions}

Our results enable us to say that the need for teeth care is proven in patients received for orthodontic consultation in the Dental Surgery Unitat Yalgado Ouédraogo Teaching Hospital. Esthetics remains an important factor in the quest for orthodontic treatment.

The aesthetic deficit is source of psychological impact that should be taken into account when assessing the need for treatment. The female population, more concerned with their appearance, seems more interested in repairing their malocclusions. The pathologies listed are diverse, including dental congestion, displacement of the bone bases, dental inclusion or agenesis, overbite, open bite.

This study should be extended to a non-consulting population such as schoolchildren, to be able to generalize the results to the whole population.

\section{Conflicts of Interest}

The authors declare to have no conflicts of interest.

\section{Ethics Statement/Confirmation of Patient Permission}

Ethics approval not required. Patient permission obtained.

\section{References}

[1] Utomi, I.L. and Onyeaso, C.O. (2015) Malocclusion and Orthodontic Treatment Need of Patient Attending the Lagos University Teaching Hospital, Lagos Nigeria. Odontostomatologie Tropicale, 38, 23-30.

[2] Savanes, M., Bassigny, F. and Zenati, N. (2006) Orthodontic Treatment Need in French Schoolchildren: An Epidemiological Study Using the Index of Orthodontic Treatment Need. European Journal of Orthodontics, 28, 605-609. https://doi.org/10.1093/ejo/cj1045 
[3] Brook, P.H. and Shaw, W.C. (1989) The Development of an Index of Orthodontic Treatment Priority. European Journal of Orthodontics, 11, 309-320. https://doi.org/10.1093/oxfordjournals.ejo.a035999

[4] Vanwyk, P.J. and Drummond, R.J. (2015) Orthodontics Status and Treatment Needs of 12-Year-Old Children in South Africa Using the Dental Aesthetic Index. $S A D J, 60,334-338$.

[5] DeGuzman, L., Bahiraei, D., Vig, K.W., Vig, P.S., Weyant, R.J. and O’Brien, K. (1995) The Validation of the Peer Assessment Rating Index for Malocclusion Severity and Treatment Difficulty. American Journal of Orthodontics and Dentofacial Orthopedics, 107, 172-176. https://doi.org/10.1016/S0889-5406(95)70133-8

[6] Ngom, P.I., Diagne, F. and Richmond, S. (2005) The Need for Orthodontic Treatment. Justification and Methods of Evaluation. L'Orthodontie Française, 76, 197-202. https://doi.org/10.1051/orthodfr/200576197

[7] Richmond, S., Ngom, P.I. and Diagne, F. (2005) Orthodontic Treatment Need: The IOTN, or Index of Orthodontic Treatment Need. L'Orthodontie Française, 76, 303-308. https://doi.org/10.1051/orthodfr/200576303

[8] Jenny, J. and Cons, N.C. (1996) Comparing and Contrasting Two Orthodontic Indices, the Index of Orthodontic Treatment Need and the Dental Aesthetic Index. American Journal of Orthodontics and Dentofacial Orthopedics, 110, 410-416. https://doi.org/10.1016/S0889-5406(96)70044-6

[9] Jarvinen, S. (2001) Indexes for Orthodontics Treatment Need. American Journal of Orthodontics and Dentofacial Orthopedics, 120, 237-239.

https://doi.org/10.1067/mod.2001.114830

[10] Daniels, C. and Richmond, S. (2000) The Development of the Index of Complexity, Outcome and Need (ICON). Journal of Orthodontics, 27, 149-166. https://doi.org/10.1093/ortho/27.2.149

[11] Borzabadi-Farahani, A. and Borzabadi-Farahani, A. (2010) The Relationship between the ICON Index and the Dental and Aesthetics Components of the IOTN Index. World Journal of Orthodontics, 11, 43-48.

[12] Kok, Y., Mageson, P., Harradine, N. and Sprod, A. (2004) Comparing a Quality of Life Measure and the Aesthetic Component of the Index of Orthodontic Treatment Need (IOTN) in Assessing Orthodontic Treatment Need and Concern. Journal of Orthodontics, 31, 312-318. https://doi.org/10.1179/146531204225020625

[13] National Institute for Statistics and Demography (2016) 2016 Statistic Book. Burkina Faso, 397 p.

[14] Bourne, C.O., Balkaran, R. and Scott, E. (2012) Orthodontic Treatment Needs in Caribbean Dental Clinics. European Journal of Orthodontics, 34, 525-530. https://doi.org/10.1093/ejo/cjr037

[15] Ghijselings, I., Brosens, V., Willems, G., Fieuws, S., Clijmans, M. and Lemiere, J. (2014) Normative and Self-Perceived Orthodontic Treatment Need in 11- to 16-Year-Old Children. European Journal of Orthodontics, 36, 179-185. https://doi.org/10.1093/ejo/cjt042

[16] Ngom, P.I., Diagne, F., Dieye, F., Diop-Ba, K. and Thiam, F. (2007) Orthodontic Treatment Need and Demand in Senegalese Schoolchildren Aged 12 - 13 Years: An Appraisal Using IOTN and ICON. The Angle Orthodontist, 77, 323-330. https://doi.org/10.2319/0003-3219(2007)077[0323:OTNADI]2.0.CO;2

[17] Perillo, L., Masucci, C., Ferro, F., Apicella, D. and Baccetti, T. (2010) Prevalence of Orthodontic Treatment Need in Southern Italian Schoolchildren. European Journal 
of Orthodontics, 32, 49-53. https://doi.org/10.1093/ejo/cjp050

[18] Aikins, E.A., Dacosta, O.O., Onyeaso, C.O. and Isiekwe, M.C. (2012) Self-Perception of Malocclusion among Nigerian Adolescents using the Aesthetic Component of the IOTN. The Open Dentistry Journal, 6, 61-66. https://doi.org/10.2174/1874210601206010061

[19] Kolawole, K.A., Ayeni, O.O. and Osiatuma, V.I. (2012) Psychosocial Impact of Tooth Aesthetic on University First Year Students. International Orthodontics, 10, 96-109.

[20] Cunningham, S.J. and Hunt, N.P. (2001) Quality of Life and Its Importance in Orthodontics. Journal of Orthodontics, 28, 152-158.

https://doi.org/10.1093/ortho/28.2.152

[21] Omer, Y.T., Bouserhal, J., Hawas, N. and Abdel Moneim El Sayed, A. (2016) Association between Normative Orthodontic Treatment Need and Self-Perceived Needs among a Lebanese Population. International Orthodontics, 14, 386-398. 